\title{
The Role of Job Embeddedness and Organizational Continuance Commitment on Intention to Stay: Development of Research Framework and Hypotheses
}

\section{Yuserrie Zainuddin and Ayesha Noor}

Faculty of Industrial Management, Universiti Malaysia Pahang, Lebuhraya Tun Razak, 26300 Gambang, Pahang, Malaysia

\section{Abstract}

The purpose of this paper is to develop a research framework and hypotheses based on a thorough review of the conceptual and empirical research in organizational behavior literature. Previous research has shown that there is an important relationship between on-the-job, off-the-job embeddedness, organizational continuance commitment, and employee's intention to stay. Organizational continuance commitment is hypothesized to have a mediating effect on the relationship between on-the-job, off-the-job, and

Corresponding Author:

Ayesha Noor

uayeshanoor@yahoo.com

Received: 5 August 2019

Accepted: 14 August 2019

Published: 18 August 2019

Publishing services provided by

Knowledge E

(c) Yuserrie Zainuddin1 and

Ayesha Noor. This article is

distributed under the terms of

the Creative Commons

Attribution License, which

permits unrestricted use and redistribution provided that the original author and source are credited.

Selection and Peer-review under the responsibility of the FGIC2019 Conference Committee. intention to stay. Implications for testing these hypotheses are articulated from research and practice perspectives. Research framework from this paper will be used at the preliminary stage of the research on ICT industry that can be expected to contribute to the development of ICT workers in Malaysia.

Keywords: job embeddedness, organizational continuance commitment, intention to stay, ICT industry, Malaysia.

\section{Introduction}

In Malaysia, online businesses are rapidly displacing the traditional method of carrying out businesses amidst mortal and brick establishments. The Internet transports many useful features which include full accessibility, speed, low cost, and user-friendliness (Alias, Othman \& Loon, 2017). The e-commerce and internet are spontaneously dispersing globally, which brings different nations of the world together in a global network economy. Due to the importance of the internet, many establishments in Malaysia are converging towards the implementation of ICTs. Internet usage might be a serious issue in improving a firm's operational efficiency and market reach. The adaption and adoption of ICT in all sectors will assist in the development of a country's economic growth (Alias et al., 2017). Likewise, the government has identified the ICT industry as 
country's overall development. This has been initiated through the Eleventh Malaysia Plan (2016-2020) in which Malaysia was recognized as a high-income country (Koen, Asada, Nixon \& Rahuman, 2017).

The contributions of the ICT services, media, and content subsectors to the GDP was 5.2\% in 2010 and 5.5\% in 2015 (Eleventh Malaysia plan: Driving ICT in the knowledge economy 2015). Malaysia has taken the third position in the world's most famous IT outsourcing location after India and China for the last ten years (Yap, Lim, Jalaludin, \& Lee, 2016). Besides that, the ICT sector is one of the major sources of employment, with about $60.9 \%$ of the total employment rate per annum. The share of ICT to the economy increased to 18.2\% in 2016 from 16.5\% obtained in the year 2010 (Table 1.1). Similarly, ICT contributed to GDP by $13.4 \%$ while e-Commerce contributed $4.8 \%$ in the year 2016. However, employment in the ICT industry rose by $4.2 \%$ in the year 2016 . At the same year, ICT manufacturing recorded the highest employment with a share of $39.7 \%$, followed by ICT service, which was $27.9 \%$ (Department of Statistics Malaysia 2015)

TABLE 1: Percentage share of ICT to Economy, 2010-2016.

\begin{tabular}{|l|c|c|c|c|c|c|c|}
\hline Years & $\mathbf{2 0 1 0}$ & $\mathbf{2 0 1 1}$ & $\mathbf{2 0 1 2}$ & $\mathbf{2 0 1 3}$ & $\mathbf{2 0 1 4}$ & $\mathbf{2 0 1 5}$ & $\mathbf{2 0 1 6}$ \\
\hline ICT & 12.9 & 11.9 & 11.7 & 12.0 & 12.4 & 13.1 & 13.4 \\
\hline E-Commerce & 3.6 & 4.0 & 4.2 & 4.4 & 4.6 & 4.7 & 4.8 \\
\hline Contribution of ICT & 16.5 & 15.9 & 15.9 & 16.4 & 17.0 & 17.8 & 18.2 \\
\hline To economy (RM Billion) & $135.3 \mathrm{~b}$ & $144.4 \mathrm{~b}$ & $154.6 \mathrm{~b}$ & 167.4 & $188.4 \mathrm{~b}$ & $206.1 \mathrm{~b}$ & $224.0 \mathrm{~b}$ \\
\hline
\end{tabular}

Source: (Dep. Stat. Malaysia 2015-2017)

This study will focus on the ICT industry as it has a greater impact on the Malaysian industrial sector. Besides this, the industry (ICT) may not be accomplishing their target growth due to a lack of skilled professionals. In Malaysian ICT industries, the turnover rate is often relatively high among certain groups of people such as professionals (Lim, 2018). From the last decade to recent, most of the industries are facing the issue related to an employee leaving (Latif, Delaila, \& Saraih, 2016). According to the Malaysian employment statistics, the ICT industry showed a 23.1\% turnover rate which was the highest of all the organizations in Malaysia (Radford, 2013-2016; Global salary increase and turnover, 2015). It shows that turnover has become a serious problem to the extent that the IT companies in Malaysia are facing the problem of retaining their skilled employees. So, it is essential for IT companies in Malaysia to increase their current employees' decision to stay.

In order to investigate employee intention to stay, several motivations are employed to clarify this technique. Most of the time, employers could not identify the reason 
why employees are quitting. Only practical information regarding employees to quit is not enough to separate the terminations of voluntary and involuntary turnover. If the termination records were undecided, then the results of studies can turn out to be wrong (Govaerts, Kyndt, Dochy, \& Baert, 2011). Furthermore, the decision to quit might be non-work related issues (family, friends, community activity, etc.) which influence them to go out of the workplace. In the meantime, Job embeddedness was established as one of the best predictors of intention to stay so that the attempt has to be determined to understand the relationship between this predictor variable to other variables. Although, few studies had investigated the relationships among community elements (fit community, sacrifice community and link community), and organization elements (fit organization, sacrifice organization and link organization) which include the employee intention to stay and continuance commitment in Asian's environment, especially in Malaysia's ICT industries with the combination of job embeddedness and social exchange theory. However, this present study investigates the divergence in the knowledge field by distinguishing this relationship (Ahmad \& Daud, 2016). Because the two parameters are in a relationship to stay, management of the organization needs to appraise good continuance commitment to the society. Then, it is anticipated that the investigation of these relationships on the intention to stay will provide full knowledge of the best methods (Ramesh \& Gelfand, 2010; Naim \& Lenka, 2016).

\section{Literature Review}

\subsection{Intention to stay}

Intent to stay is clearly elucidated as the employees are willing to stay in his/her current job (Naim \& Lenka, 2017). Most of the previous studies explored job commitment and confirmed that when a member is committed to their work and are pleased with their present job, their tendency of living is lower. In the literature on intention studies, the terms leave and stay are being used interchangeably (Ngoc, Phuong, Chi, \& City, 2018). Various parameters can affect employees in the interpretation of intention; therefore, when investigating turnover, investigators have a tendency of focusing on turnover intention rather than employee's actual intention to stay. Thus, intention suggests the way an individual behaves in an unconstrained environment. Since the intention to remain on a job is strongly predicted by the turnover, there is a high possibility that the factors influencing worker's intent would affect the turnover and retention (Zin, Pangil \& 
Othman, 2012; Mika, Vanhala, Heilmann \& Salminen, 2016). Therefore, the term intention to stay has been employed for constancy and clarity in this current study.

Furthermore, in search of better control and understanding of the inconsistency in the leaving measure, studies are focusing more on the reasons for staying rather than questioning employees about the reasons for their leaving. Nevertheless, it is primarily indicated that intentions are the best predictors of behaviours (Lee, Burch, \& Mitchell, 2014). Besides that, retaining an employee in an organization is an important way for human resource management (HRM) to encourage an aggressive benefit for companies, especially in ICT sectors in the current global market (Naim \& Lenkla, 2016. Findings on the advantage of securing employees in the IT industries had significantly designated that IT industries can acquire greater returns on assets, greater operating performance and higher returns on capital used (Yap et al., 2016).

\subsection{Job embeddedness}

\subsubsection{On-the-job embeddedness}

There are three organizational drives in organizational embeddedness (OE) that make workers remain on their jobs. These are fit, links, and sacrifices (Mitchell \& Lee, 2001). The ability of an individual to attain the requirement of an organization and interested in the reward of an organization is known as fit. The level or kind of relationship a worker has with his or her colleagues and performances at work is referred to as links. However, the profits a worker is willing to surrender if he or she is leaving an organization is called a sacrifice.

Fit-organization: The feeling of being compatible or comfortable with an organization, and the work environment is known as fit (Mitchell et al., 2001). An employee's self-value plans and career goals for the hereafter should fit together with higher organizational culture and instantaneous demand from the worker's job. Hence, the stronger the fit, the greater the possibility of the employees to professionally and personally attached with their organizations. Besides, fit to a firm also signifies the worker's sensitivity of comfort with their firm. Employees take into account how well he/she fits into an organization. According to Terence \& Lee, (2001), an employee considers how well his or her plans, career goals, and values for the future fit with the higher cooperate culture and the demands of their current job. Thus, when the fit is better, and the employees perceived comfort with their organization, the possibility 
of the employees to be personally and professionally attached to his or her employing institution become higher.

Links-organization: The links can be official or unofficial associations an employee has with institutions or others in the institution (Mitchell \& Lee, 2001). It is a form of connection between a worker and others, such as members of his or her team, superiors, and his or her colleagues. The healthier the level of links, the more firm and close individuals would be in their various operations in an organization. Also, link to the organization signifies personalities and familial relationships with other individuals in the organization. Mitchell \& Lee (2001) also suggested that as individuals have more tenancy in the organization, they tend to have several connections with other individuals (co-worker). Studies in organizational commitment had shown that commitment would develop from normative pressures arising from the socialization process experienced by the employee. Authors suggested that a worker who had been with their employer's firm for a longer period was more likely to have a deep-rooted relationship. Fong et al. (2017) supported this notion by suggesting that organizational tenure would ensure the creation of ties among the organization and their workers.

Sacrifice-organization: The cost of either material or psychological reimbursement that a worker is willing to forfeit by quitting a job is the sacrifice organization. For instance, it means quitting an organization possibly will lead to individual losses such as surrendering colleagues, fascinating tasks, or financial dividends. When a worker discovers that what he or she is giving is significant, the workers may not want to quit the organization (Holtom, Tidd, Mitchell, \& Lee, 2013). Although a worker may be so concerned about salary and benefits, the control costs, which include new health care or pension plans, should be seriously considered. Other unthinking but very important benefits that potential sacrifices can bring upon individual are stability and improvement regarding the job. Also, when a worker decides to remain on his or her job, benefits such as promotion or pension are thoroughly enjoyed (Albdour et al. 2014).

\subsubsection{Off-the-job embeddedness}

The communities embeddedness were presented by Mitchell et al., (2001) as workplace external constraint that makes persons remain wherever they reside. This construct usually influences both the work and family life of a worker. It includes the following: institutional resources, transportation, the contiguous natural settings, neighbors' and demographic profiles (school systems), professional network services, and social support systems (Gonzalez, Ragins, Ehrhardt, \& Singh, 2018). 
Fit-Community: Physically powerful bond to members of a close extended family gives gratification to the inhabitants as a result of the needs-supplies (babysitting, family gatherings for holidays, dining, or birthday celebrations), thereby making members remain in the immediate geographical location. Certainly, the community-saved viewpoint of urban communities has been known to promote community fits, such as inclusion, compatibility, and belongingness (Mensele \& Coetzee, 2014). Therefore, this situation helps to establish employees or their close family members (children and spouses) in a community where they reside. Also, fit to community signifies worker's sensitivity of comfort with his or her environment. Workers are considering how effectively he or she fits into the surrounding and community. The community and environment can make individuals meaningful, which will improve an individual's attachment to them(Treuren \& Fein, 2018). When the fit is better, and the community is in comfort, it is highly possible that the employees would experience a relationship with the institutions that employed them.

Links community: Regular and strong quality relationship with loved ones (employee's parents and children's cousins) through the social exchange of valued resources, generates unbreakable bond or links. It is asserted by Conservation of Resources (COR) theory that the motivation of people to continually increase their resources will make them desire to invest their resources in the most profitable(Gonzalez et al., 2018). Closing to family members is of great value to individuals (help with childcare and tasks) because they will always want to promote relationships to strengthen links in order to continually receive more benefits including caring for elderly parents by the adult children (Darrat et al., 2017). Additionally, a link to the community represents individuals' formal and informal relationships with their community. Scholar has described that a volume of strand tied a worker and his families in the financial, psychological, and social web that includes non-work friends, groups, and community. When the number of the relationship between the web and individual increases, the individual would become more tied to his/her organization and job Mitchell et al., (2001).

Sacrifices community: Due to an excellent family bond that cannot be simulated easily from the community, supplies from the loved ones turn out to be sacrificed (Ghosh \& Gurunathan, 2015). This kind of non-transferable assistance from kinships (siblings lending emotional comfort during the divorce, retired parents who drive them to school) are important to the concerned persons to meet the requirements of the job to reduce any form of 'family-to-work' conflict. Also, because persons are encouraged to protect the healthiness and emotional well-being of their family members (children's health, 
spouse/partner's health), individuals may not want to relocate their loved ones so as not to forfeit the benefits derived from the family members (Treuren \& Fein, 2018).

\subsubsection{Organizational continuance commitment}

Organizational commitment is a common concept for education and commerce, as shown through many previous studies. Though numerous studies have supported organizational commitment, there are several points of contentions regarding explanations, results, and the definition of the variable. Continuance commitment can improve as personnel recognizes not only the cost of leaving but the manner their skills or competencies have improved through their organization membership (Vandenberghe, Panaccio, \& Ben Ayed, 2011). What differentiates continuance from affective commitment is that workers with higher affective commitment stay in their jobs because they intend to stay while employees with higher continuance commitment stay because they must remain in their job. Allen \& Meyer (2001) have recognized that normative commitment is a kind of commitment that deals with a feeling of moral responsibility to stay in an organization. What all these three dimensions of organizational commitment commonly possess is that they all signpost the level to which employees are willing to remain in an organization. In this study, the one-dimensional technique was employed since continuance commitment is mostly connected to employees' decision to stay.

\section{Research Framework and Hypothesis}

The framework of this research stretches an explanation of how the variable connects. The different variables for this are the independent, dependent, and mediator. Independent variable influences and determines the effect of another variable with the relationship of a mediator.

\subsection{Hypotheses development}

A hypothesis can be referred to as a hesitant description of sophisticated guess about a result of the research problem, or likely result of the study (Sekaran \& Bougie, 2016). In another term, the hypothesis is described as a declaration suggested as an observation or a knowledge but has not yet been proved or disproved(Rea \& Parker, 2014). 


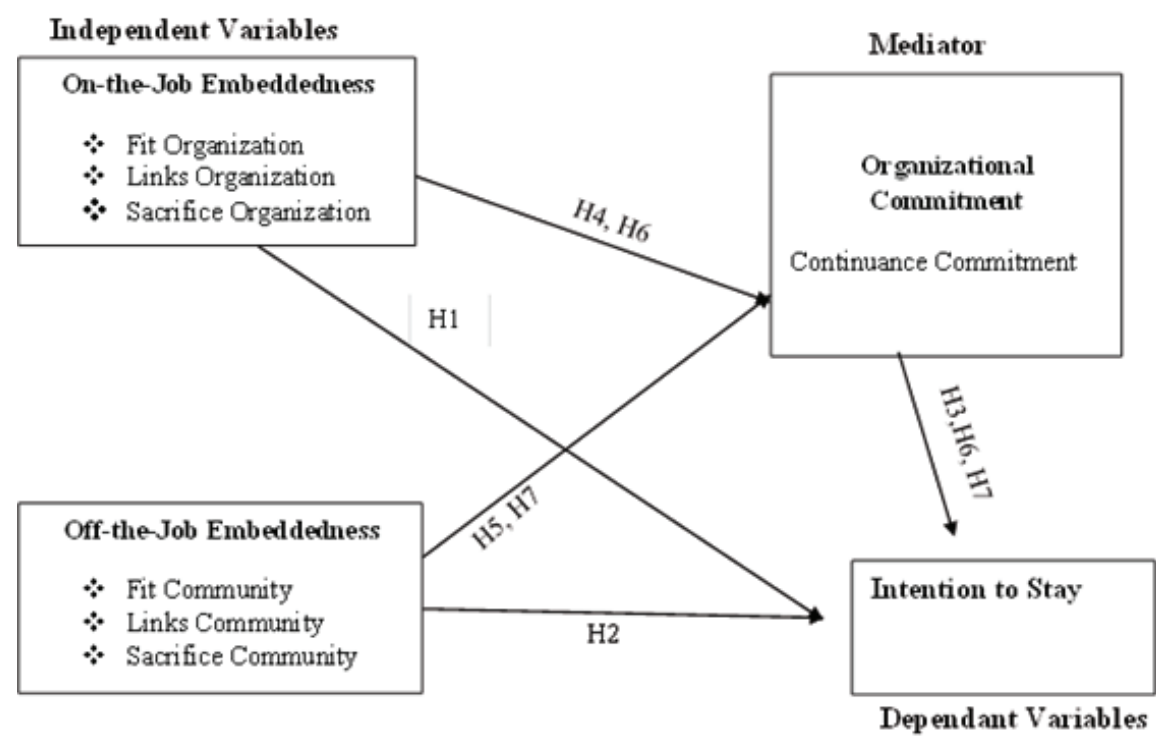

Figure 1: Research Framework.

\subsubsection{Relationship between on-the-job embeddedness and intention to stay.}

$\mathrm{H1}$ : There is a significant connection amongst intent to stay and on-the-job embeddedness in the organization.

On-the-job embeddedness is comprised of three dimensions; Fit organization, Link organization, and Sacrifice organization in which all the elements of on-the-job embeddedness will have a positive relationship with employees intend to stay in an organization. Also, it is a proposition that these elements of on-the-job embeddedness would influence the aim to stay. The more the fit, link, and sacrifice between web and person, the higher the bond between an establishment and an employee intention to stay(Heritage et al., 2016). Moreover, when on-the-job embeddedness is higher, satisfied employees would be less likely to turn away from their organization in relative to when on-the-job embeddedness is lesser because employees being highly embedded to their job draw more positive energy from being satisfied with it, which keeps them away from leaving their organization.

Conversely, studies had shown a consequential negative correlation between intention to stay and on-the-job embeddedness (Meyer et al., 1991; Crossley et al., 2007; Halbesleben \& Wheeler 2008). On-the-Job embeddedness can estimate retention rate more than ease of movement measure and perceived desirability. It had been emphasized that satisfied employees and highly embedded are not likely to look for another job opportunity (Ramesh \& Gelfand, 2010). In contrast, embedded employees 
may be emotionally perplexed in unfavourable jobs, and this might lead to frustration and loss of motivations as a result of the anxiety of losing their relationships with the organization or sacrifices they would have to make if they should consider quitting their jobs. Recently, the study centre of attention is on the positive portions of job embeddedness, which are backbones that make people satisfied and to stay in their jobs. Below are the sub-hypotheses depicted for the relationship between intention to stay and on-the-job embeddedness.

$\mathrm{H}_{1 a}$ : There is a significant connection among the fit organization and intention to stay in the organization.

$\mathrm{H}_{1 b}$ : There is a significant connection among link organization and intention to stay in the organization.

$\mathrm{H}_{1 c}$ : There is a significant connection among sacrifice organization and intention to stay in the organization.

\subsubsection{Relationship between off-the-job embeddedness and intention to stay.}

$\mathrm{H} 2$ : There is a significant positive relationship between off-the-job embeddedness and intention to stay in the organization.

Off-the-job embeddedness comprised of three dimensions; link, fit, and sacrifice community, which usually influences both the work and family life of a worker. Therefore, it is very clear that individual has more off-the-job embeddedness will have less chance to quit the organization due to more attachment. Based on this assumption, there is the proposition that employee with high off-the-job embeddedness will require a constructive connection in member decides to stay in an organization (Treuren \& Fein, 2018). If the level of off-the-job embeddedness is more, there will be lesser turn away from an organization by the satisfied employees in relative to a lower level of off-thejob embeddedness because there will be no reason for leaving. Being strongly tied to communities outside the workplace and satisfied with a person's job can result in a higher chance of staying in the job.

Despite the off-the-job embeddedness-turnover correlation had been invented (Holtom et al., 2006; Mitchell et al., 2001), several studies had suggested that offthe-job parameters are not essential in minimizing turnover intention compared to onthe-job parameters for different reasons. Firstly, powerful community embeddedness can stimulate soft turnover because an individual will possesses higher contact based on local job opportunities. Secondly, off-the-job parameters can impose higher impact 
only when geographic relocation is necessary(Dawley \& Andrews, 2012). Also, previous studies had outlined that off-the-job parameters like integration in a community and family are essential consideration why employees remain with an organization. Studies provided the impacts of family attachments and work-family conflicts. Other nonwork commitments are hobbies and religion (Treuren, 2009). These parameters are relationships to work teams, unions, or other colleagues; this was called constituent commitments. The second hypothesis in this study is about the important connection between off-the-job embeddedness and intention to stay in the organization. Below are the sub-hypotheses depicted for the connection between intention to stay and off-the-job embeddedness.

$\mathrm{H}_{2 a}$ : There is a significant connection among the fit community and intention to stay in the organization.

$\mathrm{H}_{2 b}$ : There is a significant connection among link community and intention to stay in the organization.

$\mathrm{H}_{2 c}$ : There is a significant connection among sacrifice community and intention to stay in the organization.

\subsubsection{Relationship between continuance commitment and intention to stay}

One major objective of this study is to identify the relationship between intention to stay and continuance commitment. The relationship has previously been discussed in a section. There are dense pieces of literature about the relationship between continuance commitment and intention to stay in the organizations(Umoh, Amah, \& Wokocha, 2014). Intention to stay and continuance commitment relationships have generally been conceptualized within the 'attitude-intention-behaviour' approach. Accordingly, commitment theory had suggested that the strength of an individual's ties with the organization determines how strongly he or she will engage in withdrawal cognitions, and ultimately whether or not he or she will leave the organization (Allen \& Meyer, 2001; Dyk \& Coetzee, 2013).

Ruokolainen (2011) investigated a model for employee retention. Their study sample involved 24,829 Chinese employees in the tourism and hotel industries. The obtained results established that continuance commitment was part of the most very important parameters considered in staying in an organization. Similarly, a study carried out in the banking sector by Dyk \& Coetzee (2012) showed a positive relationship between these two concepts, it also established that corporate culture had a moderating impact on 
the relationship between continuance commitment and intention to stay. Another study conducted by the Chinese researchers who got their surveyed data from nursing staffs about the occupational commitment which is a modified type of organizational commitment concluded that intention to stay and continuance commitment had a positive relationship. However, age and job position are the mediating factors in this relationship. Dyk \& Coetzee (2012) studied the relationship between retention and organizational commitment by utilizing surveyed data from 206 employees who work in the ICT and medical companies situated in South Africa. Their obtained results reflected a significant positive relationship between the two parameters and make the claim that factors including race, gender, tenure groups, and age can influence the relationship between the two parameters. Thus, this present study expected that continuances commitment will have a significant positive relationship with the intention to stay in an organization.

H3: There is a significant connection among intention to stay and continuance commitment in the organization.

\subsubsection{Relationship between on-the-job embeddedness and continuance commitment.}

$\mathrm{H} 4$ : There is a significant connection among continuance commitment and on-the-job embeddedness.

On- the-job, embeddedness and continuance are tied in that they seek to define the turnover of a worker in a firm. Generally, the study begins off with a turnover by focusing on work attitudes like organizational commitment and job satisfaction. Job embeddedness is independently related to turnover and other local turnover models. Besides, continuance commitment is different from job embeddedness in that it is a work attitude conceptualized to understand why workers quit. Notably, a study on turnover moved away from forecasting why worker quit to understanding why workers stay and incorporating on-the-job factors in this decision to stay.

Therefore, an employee may willingly stay due to personal investments that are not transferable which include career investments and retirement investments, close working relationship with co-workers, unique acquired job skills known to the organization, involvement in the organization, years of employment in a particular organization, and other benefits that make it too costly for one to leave and seek employment in other places(Ferreira \& Coetzee, 2013). This study expected that continuances commitment will have a significant relationship with on-the-job embeddedness in an organization. 
Below are the sub-hypotheses depicted for the connection between continuance commitment and on-the-job embeddedness.

$\mathrm{H}_{4 a}$ : There is a significant connection among the fit organization and continuance commitment.

$\mathrm{H}_{4 b}$ : There is a significant connection among link organization and continuance commitment.

$\mathrm{H}_{4 c}$ : There is a significant connection among sacrifice organization and continuance commitment.

\subsubsection{Relationship between off-the-job embeddedness and continuance commitment.}

H5: There is a significant connection among continuance commitment and off-the-job embeddedness.

Continuance commitment describes the employees' emotional attachments to be involved with the organization and their goals. It emanates the employees' and organizational value congruence. Due to this, it is normal for an employee to become emotionally attracted to his/her job and continuing enjoying membership in the organization (Holtom et al., 2006; Mitchell et al., 2001). Lee et al. (2014) stated the parameters that assist in creating intrinsically rewarding occurrences for employees to be antecedents of continuance commitment. These parameters are task significance, identity, autonomy, feedback concerning employee job performance, skills variety, perceived organizational dependence, or support. Below are the sub-hypotheses depicted for the relationship between continuance commitment and off-the-job embeddedness.

$\mathrm{H}_{5 a}$ : There is a significant connection among the fit community and continuance commitment.

$\mathrm{H}_{5 b}$ : There is a significant connection among links community and continuance commitment.

$\mathrm{H}_{5 c}$ : There is a significant connection among sacrifice community and continuance commitment.

\subsection{6. "The mediation role of continuance commitment on the relation- ship between on-the-job embeddedness and intention to stay."}

H6: Continuance commitment mediates the relationship among intention to stay and on-the-job embeddedness. 
The three types of organizational commitment, which includes continuance, affective, and normative earlier discussed, can produce various levels of relationship with the different variable; intention to stay (Dockel et al., 2012). The outcomes from their study established that continuance commitment corresponds intending to stay. However, continuance commitment had the best relationship with the intent to stay. The role of continuous commitment can be altered in the presence of different demographics in young age groups; this type of commitment can be less proactive due to inexperience about their value in the organization. The young employee has less likelihood to know about the consequences of leaving the job. Similarly, another study conducted on health professionals affirmed that a continuance commitment had a constructive influence on the intention to stay (Ahmad \& Daud, 2016). The variables mediated in the study through separation. Like the other two dimensions of organizational commitments, studies had shown that continuance commitment had a noticeable affirmative correlation with the intention to stay. Also, job embeddedness construct symbolizes "a wider set of impacts on the employees' decisions to stay on their job" (Tanova \& Holtom, 2008).

$\mathrm{H}_{6 a}$ : Continuance commitment mediates the relationship among the fit organization and intention to stay.

$\mathrm{H}_{6 b}$ : Continuance commitment mediates the relationship among links organization and intention to stay

$\mathrm{H}_{6 c}$ : Continuance commitment mediates the relationship among sacrifice organization and intention to stay.

\subsection{7. "The mediation role of continuance commitment on the relation- ship between off-the-job embeddedness and intention to stay."}

H7: Continuance commitment mediates the relationship between intention to stay and off-the-job embeddedness.

It is a feeling of accountability to continue with an organization" (Allen \& Meyer, 2001). Such a feeling of duty often emanates from what is called "generalized values of duty and loyalty." This refers to a natural predisposition of being committed and loyal to an institution like marriage, family, employment organization, religion, a country because of cultural socialization that places a premium on devotion and loyalty to the institution". "This feeling of moral obligation is determined through the length at which a person feels that he/she should be loyal to his/her organization, making a personal sacrifice to criticize or improve it”(Dyk \& Coetzee, 2012). Below are the sub-hypotheses depicted 
for the relationship between off-the-job embeddedness, continuance commitment, and intention to stay.

$\mathrm{H}_{7 a}$ : Continuance commitment mediates the relationship among a fit community and intention to stay.

$\mathrm{H}_{7 b}$ : Continuance commitment mediates the relationship among links community and intention to stay

$\mathrm{H}_{7 c}$ : Continuance commitment mediates the relationship among sacrifice community and intention to stay.

\section{Future Research and Implications}

This study represents the research framework that will lead our empirical effort in the area. The testing of this framework will contribute to the literature by examining the relationship of job embeddedness, organizational continuance commitment, and employees' intention to stay.

Many contributions can be made to theory based on the outcomes of this study. Firstly, the use of community psychology and sociological literature enrich the theory of job embeddedness and provide a higher technique to understand the function of community relationships and off-the-job embeddedness in organizational life. These theoretical points of view enhance one another. Social points of view explain a means the relationship between family and friends within a community influence the community attachment; however, the theory of job embeddedness outlines the processes by which community relationships join people to their workplaces. This study also provides an improved analysis by differentiating the relationship with family and friends. This provides a theoretical explanation of the distinct influences of family and friends bonds on the workplace attachment and employees' community. Hence, the current study provides a new hypothetically driven understanding of work-life scholars and job embeddedness in relation to the role of community relations in organizational life.

The result obtained from this study can help to enhance retention programs for both employees and employers. Likewise, the acquired data can reflect the significant factors towards the employee intention to stay. This can assist the ICT companies in focussing more on how the problem will be solved. Furthermore, this will assist the employers in commencing preventive measures that can strengthen the relationship between employer and employee, leading to an improve employee's loyalty. Additionally, the government can employ the results from this finding as a template for re-evaluating the present policy in retaining an employee in an establishment. New policies in ICTs 
industries can be developed by the government, which can serve as benefits and compensations that will encourage more commitments from the employees. Moreover, this finding can be generalized in other developing countries of a similar nature. Usually, it would be difficult to generalize the findings of one country to another, but ICT industries are facing a similar type of problems and hurdles in almost all the developing nations. Therefore, it could be considered as the case study of these nations. Findings of this study can be customized according to the situation of the ICT industries in other developing countries.

\section{Acknowledgement}

We would like to thank Faculty of Industrial Management and FIM's Governance and Integrity Centre, Universiti Malaysia Pahang for the financial support by sponsoring this paper to be presented in the FGIC 2nd Conference on Governance and Integrity 2019.

\section{Funding}

Authors would like to acknowledge University Malaysia Pahang, Malaysia for providing financial support through the project GRS130371.

\section{References}

[1] Ahmad, N. A., \& Daud, S. (2016). Engaging People with Employer Branding. Procedia Economics and Finance, 35(October 2015), 690-698. https://doi.org/10.1016/S22125671(16)00086-1

[2] Albdour, A.(2014). Employee engagement and organizational commitment: Evidence from Jordan. Pdfs.semanticscholar.org.Alias, N. E., Othman, R., Loon, K. W., Ridzuan, A. R., \& Krishnan, R. (2017). Towards Effective Employee Retention Strategy: Implementation of Talent Management in Information, Communication and Technology Companies. Advanced Science Letters, 23(8), 7857-7860.

[3] Allen, N. J., \& Meyer, J. P. (2001). A three-component conceptualization of organizational commitment. Human Resource Management Review, 1(1), 61-89. https://doi.org/10.1016/1053-4822(91)90011-Z

[4] Crossley, C., Bennett, R. J., Jex, S. M., \& Burnfield, J. L. (2007). Development Of A Global Measure Of Job Embeddedness And Integration Into A Traditional Model Of Voluntary Turnover Part Of The Management Sciences And Quantitative Methods 
Commons. Journal of Applied Psychology, 92(4), 1031-1042. https://doi.org/10.1037/ 0021-9010.92.4.1031

[5] Darrat, M. A., Amyx, D. A., \& Bennett, R. J. (2017). Examining The Impact Of Job Embeddedness On Salesperson Deviance: The Moderating Role Of Job Satisfaction. Industrial Marketing Management, 63, 158-166.

[6] Dawley, D. D., \& Andrews, M. C. (2012). Staying put: Off-the-job embeddedness as a moderator of the relationship between on-the-job embeddedness and turnover intentions. Journal of Leadership and Organizational Studies, 19(4), 477-485. https: //doi.org/10.1177/1548051812448822

[7] Department of statistics malaysia 2015-2017.

[8] Dockel, A., Basson, J. S., \& Coetzee, M. (2006). The Effect Of Retention Factors On Organisational Commitment: An Investigation Of High Technology Employees. SA Journal of Human Resource Management, 4(2), 20-28.

[9] Dyk, J. V., \& Coetzee, M. (2013). Organisational commitment and job embeddedness of service staff with critical and scarce skills. South African Jounral of Labour Relations, 37(1), 61-78.

[10] Dyk, J. Van, \& Coetzee, M. (2012). Retention factors in relation to organisational commitment in medical and information technology services.

[11] Eleventh malaysia plan: Driving ICT in the knowledge economy 2015.

[12] Ferreira, N., Basson, J., \& Coetzee, M. (2010). Psychological Career Resources In Relation To Organisational Commitment:An Exploratory Study. SA Journal of Human Resource Management, 8(1), 1-10.

[13] Ferreira, N., \& Coetzee, M. (2013). The influence of job embeddedness on black employees ' organisational commitment. Southern African Business Review, 17(3), 239-255.

[14] Fong, V. (2017). the Role of Culture and Commitment on Job Embeddedness and Stay Intention in Hong Kong. Desertation Doctor of Business Administration, (September).

[15] Ghosh, D., \& Gurunathan, L. (2015). Job Embeddedness: A Ten-year Literature Review and Proposed Guidelines. Global Business Review, 16(5), 856-866. https://doi.org/ 10.1177/0972150915591652

[16] Gonzalez, J. A., Ragins, B. R., Ehrhardt, K., \& Singh, R. (2018). Friends and Family: The Role of Relationships in Community and Workplace Attachment. Journal of Business and Psychology, 33(1), 89-104. https://doi.org/10.1007/s10869-016-9476-3

[17] Govaerts, N., Kyndt, E., Dochy, F., \& Baert, H. (2011). Influence of learning and working climate on the retention of talented employees. Journal of Workplace Learning, 23(1), 35-55. https://doi.org/10.1108/13665621111097245 
[18] Halbesleben, J. R. B., \& Wheeler, A. R. (2008a). The Relative Roles Of Engagement And Embeddedness In Predicting Job Performance And Intention To Leave. Work and Stress, 22(3), 242-256. https://doi.org/10.1080/02678370802383962

[19] Heritage, B., Gilbert, J. M., \& Roberts, L. D. (2016). Job embeddedness demonstrates incremental validity when predicting turnover intentions for Australian university employees. Frontiers in Psychology, 7(APR), 1-12. https://doi.org/10.3389/fpsyg. 2016.00582

[20] Holtom, B. C., Mitchell, T. R., \& Lee, T. W. (2006). Increasing human and social capital by applying job embeddedness theory. Organizational Dynamics, 35(4), 316-331. https://doi.org/10.1016/j.orgdyn.2006.08.007

[21] Holtom, B. C., Tidd, S. T., Mitchell, T. R., \& Lee, T. W. (2013). A demonstration of the importance of temporal considerations in the prediction of newcomer turnover. Human Relations, 66(10), 1337-1352. https://doi.org/10.1177/0018726713477459

[22] Koen, V., Asada, H., Nixon, S., \& Rahuman, M. (2017). Malaysia’s economic success story and challenges.

[23] Latif, A., Delaila, F., \& Saraih, U. (2016). Factors Influencing Employee Turnover in Private Sector in Malaysia: A Concept Paper.

[24] Lee, T. W., Burch, T., \& Mitchell, T. R. (2014). The Story of Why We Stay: A Review of Job Embeddedness. Ssrn, 199-218. https://doi.org/10.1146/annurev-orgpsych031413-091244

[25] Lim, L. (2018). Preliminary study of Intention to Stay among the IT Employees in Klang Valley, Preliminary study of Intention to Stay among the IT Employees in Klang, ( July).

[26] Mensele, C., \& Coetzee, M. (2014). Job embeddedness, organisational commitment and voluntary turnover of academic staff at a higher education institution in South Africa. South African Journal of Labour Relations, 38(1), 9-30.

[27] Meyer, J.,\& Allen, N. (1990). Affective And Continuance Commitment To The Organization: Evaluation Of Measures and Analysis Of Concurrent And TimeLagged Relations. Psycnet.apa.org.Meyer, J. P., Bobocel, D. R., \& Allen, N. J. (1991). Development of Organizational Commitment During the First Year of Employment: A Longitudinal Study of Pre- and Post-Entry Influences. Journal of Management, 17(4), 717-733. https://doi.org/10.1177/014920639101700406

[28] Mika, V., Pia, H., \& Hanna, S. (2016). Organizational Trust Dimensions as Antecedents of Organizational Commitment. Knowledge and Process Management, 23(1), 46-61. https://doi.org/10.1002/kpm 
[29] Mitchell, T. R., Holtom, B. C., Lee, T. W., Sablynski, C. J., \& Erez, M. (2001). Why people stay: Using organizational embeddedness to predict voluntary turnover. Academy of Management Journal, 44(6), 1102-1121. https://doi.org/10.2307/3069391

[30] Mitchell, T. R., \& Lee, T. W. (2001). Voluntaryturnoverandjob Embeddedness: Foundations Foracomprehensivetheory Ofattachment. Research in Organization Behavior, 33, 189-246.

[31] Naim, M. F., \& Lenka, U. (2017). Mentoring, social media, and Gen Y employees' intention to stay: towards a conceptual model. International Journal of Business and Systems Research, 11(1/2), 28. https://doi.org/10.1504/IJBSR.2017.080832

[32] Naim, M. F., \& Lenka, U. (2016). Knowledge sharing as an intervention for Gen Y employees' intention to stay. Industrial and Commercial Training, 48(3), 142-148. https://doi.org/10.1108/ICT-01-2015-0011

[33] Ngoc, N., Phuong, D., Chi, H., \& City, M. (2018). Key Determinants And Effect Of Organizational Commitment On Employee' S Intention To Stay: A PLS-SEM, (September). https://doi.org/10.7456/1080SSE/171

[34] Radford 2013-2016;Global salary increase and turnover 2015.

[35] Ramesh, A., \& Gelfand, M. J. (2010). Will they stay or will they go? The role of job embeddedness in predicting turnover in individualistic and collectivistic cultures. Journal of Applied Psychology, 95(5), 807-823. https://doi.org/10.1037/a0019464

[36] Rea, L. M., \& Parker, R. A. (2014). Using focus groups in the survey research process. In Designing and Conducting Survey Research: A Comprehensive Guide (pp. 8095).

[37] Ruokolainen, M. (2011). Do Organizational And Job-Related Factors Relate To Organizational Commitment?: A Mixed Method Study Of The Associations. Jyväskylä studies in education, psychology and social.

[38] Sekaran, U., \& Bougie, R. (2016). Research methods for business: a skill-building approach / Uma Sekaran and Roger Bougie. Nucleic Acids Research (Vol. 34).

[39] Tanova, C., \& Holtom, B. C. (2008). Using job embeddedness factors to explain voluntary turnover in four European countries. International Journal of Human Resource Management, 19(9), 1553-1568. https://doi.org/10.1080/09585190802294820

[40] Treuren, G. (2009). Does off-the-job embeddedness matter in predicting intention to leave?, 1-25. Retrieved from http://search.ror.unisa.edu.au/ record/UNISA_ALMA11143324640001831/media/digital/open/9915910969101831/ $12143324630001831 / 13143321870001831 / p d f$

[41] Treuren, G. J. M., \& Fein, E. C. (2018). Off-the-job embeddedness as a moderator of the relationship between work and life conflict and turnover intention. International 
Journal of Human Resource Management, O(0), 1-22. https://doi.org/10.1080/ 09585192.2018.1510847

[42] Umoh, G. I., Amah, E., \& Wokocha, I. H. (2014). Employee Benefits and Continuance Commitment in the Nigerian Manufacturing Industry. IOSR Journal of Business and Management Ver. II, 16(2), 69-74. Retrieved from www.iosrjournals.org

[43] Vandenberghe, C., Panaccio, A., \& Ben Ayed, A. K. (2011). Continuance commitment and turnover: Examining the moderating role of negative affectivity and risk aversion. Journal of Occupational and Organizational Psychology, 84(2), 403-424. https://doi. org/10.1348/096317910X491848

[44] Yap, C. S., Lim, Y. M., Jalaludin, F. W., \& Lee, T. H. (2016). Determinants of ICT outsourcing among the locally-owned manufacturers in Malaysia. Strategic Outsourcing: An International Journal, 9(3), 324-342. https://doi.org/10.1108/SO-032016-0011

[45] Zin, L. M., Pangil, F., \& Othman, S. Z. (2012). Investigating the relationship between monetary rewards and flexible work schedule on intention to stay in ICT companies, 2(1), 1-18. 